\title{
Defining Accessibility of Open Space in Relation to Urban configuration: Case Study of Wanchai, Hong Kong
}

\author{
Ling Xiaohong ${ }^{1, a}$ \\ ${ }^{1}$ School of Architecture, South China University of Technology, Tianhe District, Guangzhou, China \\ arlingxh@scut.edu.cn
}

\begin{abstract}
Keywords: Accessibility and use of open space, urban configuration, Hong Kong, space syntax Abstract: As one of the high-density cities of the world, Hong Kong is suffering from a limited supply of land for its main urban areas; some open spaces however are frequently criticized as inconvenient for users and consequently ineffectively used. How to improve the performance of open spaces is, therefore, a critical issue faced by the city planners. As the conventional accessibility model, which is described mainly with respect to maximum walking distance or service radius, is inadequate to give an account of the issue, this study accordingly indicates an alternative approach and seeks an explanation from the urban configuration and the way it conditions accessibility. Through investigating the relationship between urban configuration and the access and use of open spaces based on the Wanchai District of Hong Kong, which particularly epitomizes various urban grids that may have different consequences on the use of open space, the study attempts to examine whether there is a consistent relationship existing in different grid patterns or whether the relationship varies between different grids. It is hope that the findings can be used to help improve the performance of open spaces in the urban areas of Hong Kong and other similar urban environment.
\end{abstract}

\section{Introduction}

The existence of urban open space plays an important role in people's lives, especially in highdensity cities such as Hong Kong. Owing to the constraints of natural settings and the increasing demands from rapid population and economic growth, Hong Kong is suffering from a limited supply of land for development, especially in its urban areas. The insufficient land supply has led to the need to optimize the land utilization, further requiring a high-rise and high-density development pattern [1]. While the residents of Hong Kong in general have accepted high-density living as a way of life, a common criticism of the city is that it has produced an overcrowded urban environment, together with serious air pollution issues. In this regard, being deemed an evident measure to overcome the negative impact of intensive development, provision of open space was then introduced in the planning process.

However, the provision has been moderate in the dense urban areas. Whilst the supply of open space was inadequate to meet the increasing demands, some spaces were located in the sites inconvenient for users, consequently leading to a low level of uses. What is wrong with these spaces? Among the reasons for this, is that their location is wrong [2]. When the economic policy adopted in Hong Kong was laissez-faire or positive non-intervention so as to encourage development, it comes as no surprise that the land for commercial use was always given priority over open spaces in terms of economic justification, and the locational qualities of open spaces were frequently neglected in the site selection. When focusing on human needs, the location of open space can be interpreted as an accessibility problem, which has been confirmed to be a basic requirement for the use of open spaces $[3,4,5]$. In truth, in order to provide readily accessible recreational open spaces for the public, a hierarchical principle actually has been highlighted in planning process. That is, open spaces fulfill different functions with increasing size and distance from a given area or population (Fig.1). In light of this principle, the location of open space is generally examined with respect to the measures, including 
maximum walking distance and service radius. An acquaintance with the spatial and social contexts is not essentially required.

As a result, the distribution of open spaces in the urban areas of Hong Kong, in most circumstances, has satisfied the recommended accessibility standards, but some of them were still criticized as inconvenient for access and use even though they possessed essential design qualities and facilities. This seems to suggest that the conventional concept with respect to walking distance alone is inadequate to provide explanations for the accessibility related issues in the real urban environment. In fact, some recent research has suggested that the hierarchical and even distribution throughout the urban fabric is not the best solution for open space provision. Open space should be integrated into urban lives, because urban morphology plays an important role in defining their performance [6].

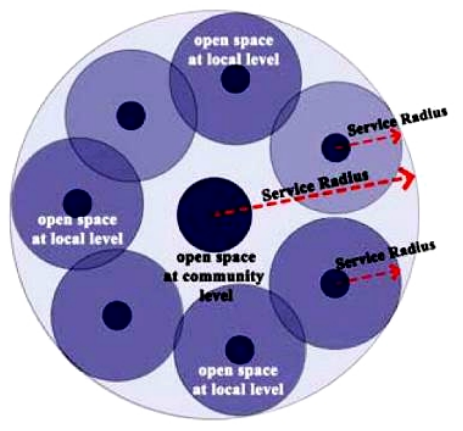

Fig. 1: The hierarchical distribution principle

The necessity of investigating the use of open spaces from the morphological point of view is also supported by the fact that, with few exceptions, cities always came into being through a process of growth and change over a long period of time so that they display neither spatial nor functional simplicity [7]. Within this spatial system, urban spaces are not homogenous and isometric, but unique and differentiated from each other with reference to the whole [8]. When open spaces are embedded within such an urban system, they are unlikely as isolated entities. Instead, each location has its unique way to associate with surroundings, not only with local environmental elements such as buildings and streets, but also with the overall plan layout. The varying associations could create different conditions for people to access and use the space. Obviously, the conventional walking distance notion cannot mirror the relationship; conversely, they tend to simplify and abstract the relationships (for example, put it in a circle).

The above explanation is also consistent with recent empirical researches [9,10,11], which have challenged the idea of disregarding the relation of open spaces with urban morphologies. The authors have implied that the attractiveness of the place alone is insufficient to account for its access and use, but the permeable and visual connections of the spaces to surrounding morphologies play an important role in their performance. In other words, except the attractiveness of the spaces, the access and use of open space by and larger is determined by their permeability and visibility quality within the urban fabric where they are embedded. These authors, however, cannot provide a precise description of how open spaces are spatially embedded in the overall urban layout, or how their location and connection with pedestrian networks creates different conditions for the people to access and use the space. Therefore, a question that can be raised is how accessibility of open spaces can be appropriately defined so that it can become a practical criterion in both research and practice.

\section{Literature review}

The concept of accessibility came into force in the 1950s. In the main, it is defined as the ability to visit activity places by using particular transport systems at an acceptable cost in terms of time or money [12]. Since the concept of accessibility was proposed, it has been applied in a wide range of fields, especially in regional science. In urban design domains, accessibility is also a key concept and an important quality of built environment. Kelvin Lynch [13] has particularly discussed the importance of access in determining the performance of a city. He points out that the very function of a city actually comprises a network of access. Discussing the significance of access mainly from the 
perspective of the socio-economic aspects of urban space, Lynch thereby put his emphasis on the transportation and communication modes, the cost, and the quality of access. In addition to Lynch, there are some other influential authors, including Carr et al. [4], who also point out that the ability to enter the space is basic to its performance. Carr et al. further suggest that the accessibility of a place can be conceptualized into three components, which are physical, visual, and symbolic access. For a space to be physically accessible, it should not only be without barriers to entry, but also be well connected to the paths of circulation. Another author Gehl [11] also lists some invitation features of a space, which can be used to evaluate the degree of access, for example, smooth transition between public and private areas, a short and manageable route, to be able to see what is going on. Indeed, these suggestions are insightful and useful; yet still tend to be abstract and at conceptual level, and not easily be employed to predict and evaluate the accessibility in both research and practice. Jiang et al. [14] in fact have pointed out that there exists a systematic problem with accessibility research in the literature. That is, "what is dramatically absent are tools for developing accessibility measures at fine spatial scales which involve the geometry of urban structures in terms of streets and buildings in contrast to the measurement of accessibility at the geographic or thematic level' [14]. One important reason for this is the lack of experimental description tool for various urban forms. In this sense, this study suggests that the theory and methods offered by space syntax may provide with an appropriate theoretical framework and analytical means.

Being developed by Hillier and Hanson at the University College London [8], space syntax is a technique that can be used for morphological analyses of buildings, architectural plans and urban areas. Space syntax is also one of the few theories, which allow the understanding of how culture and society are embedded in the specific relational patterns constituting architecture and urban design. When concerning urban issues, the analysis of space syntax focuses on the configuration of spaces, which can be generally defined as the relation between two spaces taking into account of a third or all the other spaces within a complex system. Through modeling the urban layout as a continuous whole, the configuration analysis enable the examination of "relative accessibility" of an overall layout, thus able to assign each location a certain degree of accessibility with reference to the whole (such as Rn) or with reference to its neighbors (such as R3). In other words, the accessibility of each location within an urban layout becomes predictable and comparable. The 'accessibility' concept in space syntax is defined and measured by the topological relations between urban spaces rather than by metric distance, thus able to take the effect of spatial structure of different urban layout into account.

Configuration analysis starts with the representational techniques: 'convex spaces', defined by polygons where no line drawn between any two points in the space goes outside it; 'axial lines', defined as the longest and fewest straight lines of visibility and permeability that cover all the convex spaces, represent the one-dimensional organization of the spatial layout [8]. Axial-line map is an important representation of the configuration of urban street networks in space syntax, where warmer color axial line has high global or local integration value, vice versa. To quantify the properties of configuration, depth as a basic unit is introduced into space syntax to measure the necessary steps from a given axial line that are needed to go through to another given axial line.

Based on the concept of depth, a number of syntactic variables are developed to describe the configurational properties of a plan layout. Among these variables, connectivity measures the degree of intersection or one step possibilities of each axial line. Global integration $(\mathrm{Rn})$ is a description of the level of ease or difficulty in getting to a certain line from all other lines in the system, it thereby reflects the 'relative accessibility' of certain space within the urban system as a whole. Contrastingly, Local integration (R3) is another measurement, which considers three steps from the space itself, and is also called radius-3 integration in comparison with global integration $(\mathrm{Rn})$. In addition, being accompanied with a wide range of application and analysis of space syntax in other contexts, a number of extended 
syntactic variables have also been developed. Integration core (Syntactic core), is the one helping understand syntactic centrality and major order of integration in spatial configuration [15]. Conventionally, integration core comprises $5 \%-25 \%$ of the most integrated lines of all axial lines according to the highest integration rank. In syntactic sense, integration core represents the most accessible place within the system. Hence, by examining the core features, it allows research to identify the distribution pattern of relative accessibility of a system.

Hillier [16] is probably the first one who produced a morphological analysis of open space in the city of London based on space syntax. To describe the strategic location of the space, Hillier suggested using 'strategic value' to measure the visual and permeable connection between the urban space and surrounding urban environment. Strategic value is the sum of global integration values of axial lines passing through the body urban spaces [7]. Finally, Hillier's study finds out that none of the design variables seem able to explain the use pattern in the selected urban squares; instead, a consistent relationship is found between the strategic value of urban spaces and their number of users. Another empirical study on the subject was carried out by Campos [17], who systematically investigated the morphological characteristics of public squares in both traditional European towns and the City of London. By examining thirty sample public squares in European towns, Campos developed an analytic framework to describe the permeable and visual connection between public squares and surrounding urban fabric, and then used this framework to examine the use pattern of twelve contemporary examples in the City of London. In her study, Campo not only investigates the relationship between use of public squares and configurational properties of its surrounding axial lines according to the number of axial lines, the sum and mean of the length of the axial lines, strategic values, local strategic values, and intersection points, but also examines the embedding of the squares within the whole urban layout and their implications for use. Campo's studies are comparatively insightful and comprehensive, which are deemed to provide strong support for this study to develop a holistic accessibility model for further research purpose.

To formulate the accessibility framework for further research purpose, this study then brings together all the claimed variables by previous authors, but focusing on the variables that specifically describe and measure the physical (Permeability) relationship of open spaces and its surroundings. For a more systematic structure, physical accessibility is further classified into global and local access. Global accessibility mainly deals with the locational properties of a space within the whole urban layout, for example, its relation to the global and local integrators, theoretically, the most accessible area of a layout or just in terms of its immediate neighbors. Local accessibility, by contrast, examines the association of the space with its surrounding pedestrian networks to see how the properties of its interfacing streets play a role in drawing people into and use the space. As a result, the numbers of streets and the way in which the space is interfaced are used to define local accessibility. Inspired by Hillier and Campo's studies, the integration values of surrounding streets defined as 'strategic value', is also used to measure the accessibility at the local level.

\section{Methodology}

\section{The selection of case study area}

In light of the research problems formulated, this study chooses Wanchai District of Hong Kong as the case for empirical analysis. Wanchai is located in the north of Hong Kong Island between Central and Causeway Bay, with Victoria Harbor to its north and the mountains south (Fig. 2). As one of the oldest districts of Hong Kong, its history can be traced back to 1842, when Hong Kong Island was ceded to Britain. Over the past 173 years, Wanchai has gone through rapid urban growth and 
incremental changes, which have characterized it as a unique area, mixing old and new, and mixing local inhabitants and tourists at the same time.

Resulting from the different stages of land reclamation carried out by the government, the urban fabric of Wanchai has displayed a 'segment-line' pattern ${ }^{1}$, where different characteristic urban structures are stratified chronologically from hillside to the harbor. Several main streets, Johnston Road, Hennessy Road and Gloucester Road that used to form the coastline have now become boundaries between different layout patterns. As shown in Fig.2b, the original settlement of Wanchai is located between Queen's Road and Johnston Road, where the street grid is dense and a little deformed in response to the topography, and thus can be identified as "Traditional grid"(Area 1). The urban grid between Johnston Road and Gloucester Road, which was developed from a large scale land reclamation project in the early $20^{\text {th }}$ century, is larger and more regular, clearly demonstrating a planned nature. It is, therefore, defined as "Planned grid" (Area 2) so as to differentiate from the traditional grid to its south. While in the area located to the north of Gloucester Road which was developed during the 1980s, the grid is clearly laid down based on the modernist planning principle. The grid pattern is visually sparse and not well defined by buildings, and thus is defined as "Sparse grid" in the study. In addition, a second level skywalk system has emerged in this area, connecting a number of commercial and office buildings and to some extent reinforced the complexity of the layout pattern within "Sparse grid"(Area 3). In light of the above description, it may be concluded that the first reason for choosing Wanchai as the case study area is on account of its spatial morphologies, aggregated with different layout patterns, which particularly epitomizes the various spatial pattern in the urban areas of Hong Kong. The selection of the district thus provides a satisfactory basis for the research to investigate whether there is a consistent relationship between spatial morphologies and use of open space and whether their relationship varies between different grid patterns.

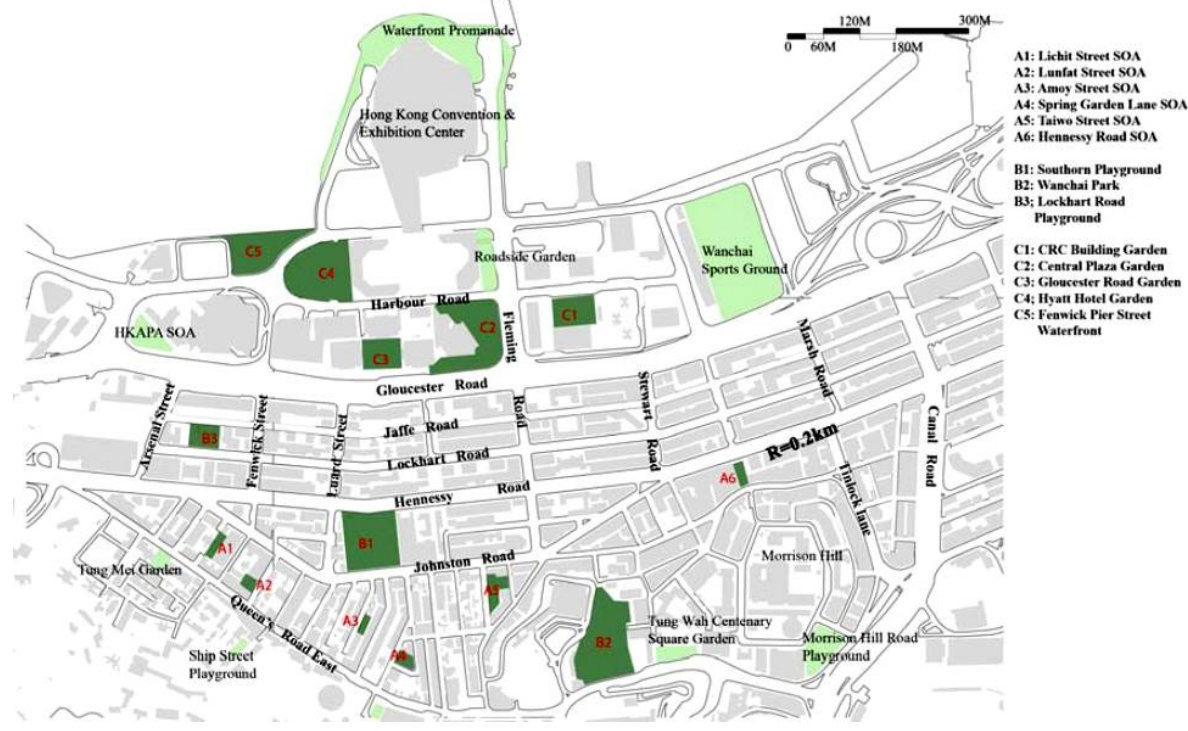

(a) Distribution of open spaces

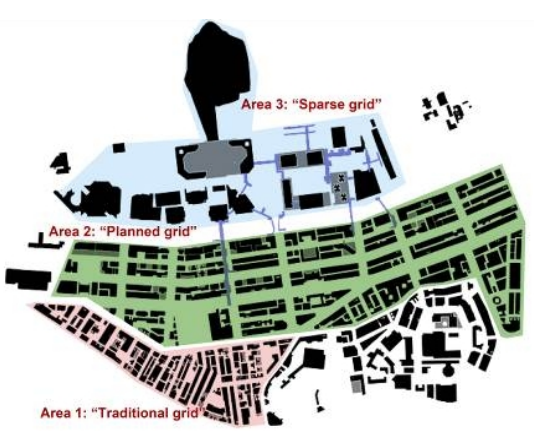

(b) 'segment-line' city

Fig. 2: Different urban grids in Wanchai District and distribution of sample open spaces

\section{The selection of sample open spaces}

Recreational open spaces in Hong Kong can be classified into two categories: active open spaces and passive open spaces ${ }^{2}$ in terms of their form, function, and facilities. But in this study, a different typology of open spaces is developed with reference to their function, size, design quality and facilities, namely, pocket parks, playgrounds, gardens and waterfront promenades. Such a classification is to 
exclude the impact from design and functional aspects. For example, through carrying out the analysis based on the same type of open spaces, the study can discount the influences from physical and functional aspects so that the effect of urban morphologies can be specifically examined. Consequently, 14 sample open spaces are selected. However, as shown by Fig. 2a, the distribution of the sample spaces seems uneven with reference to different grids, which may bring some limitations for the research. To tackle the problem, the research suggests defining "Traditional grid" and "Planned grid" as a whole, namely, a "Dense grid", because both of them demonstrate a similar grid pattern. That is, both of them are defined by buildings rather than by roads as shown in "Sparse grid".

\section{Axial-line mapping of pedestrian network in Wanchai}

Concerning the unique spatial characteristics in Wanchai, a number of contextual features are carefully identified and modeled into the map (Fig. 3a). With regard to the second-level pedestrian network located in Wanchai North, it has been found to play a critical role in the city life of Hong Kong in terms of its scale and functions. As suggested by Chang [18], the second-level skywalk system can be represented as an individual axial-line system superimposed on the overall system at ground level, being connected with transition spaces, including staircases and escalators (Fig.3b). When the axial map of Wanchai is completed in CAD, it is transferred into DEPTHMAP for processing. According to the research problem formulated, this study will focus on the accessibility related variable, such as Rn, R3, and syntactic core, and these variables will be displayed in both graphical and quantitative terms. After configurational analysis, the mapping of the pedestrian network is superimposed on a mapping of the distribution of sample open spaces to indicate their location in the complex larger system and their association with surrounding pedestrian networks.
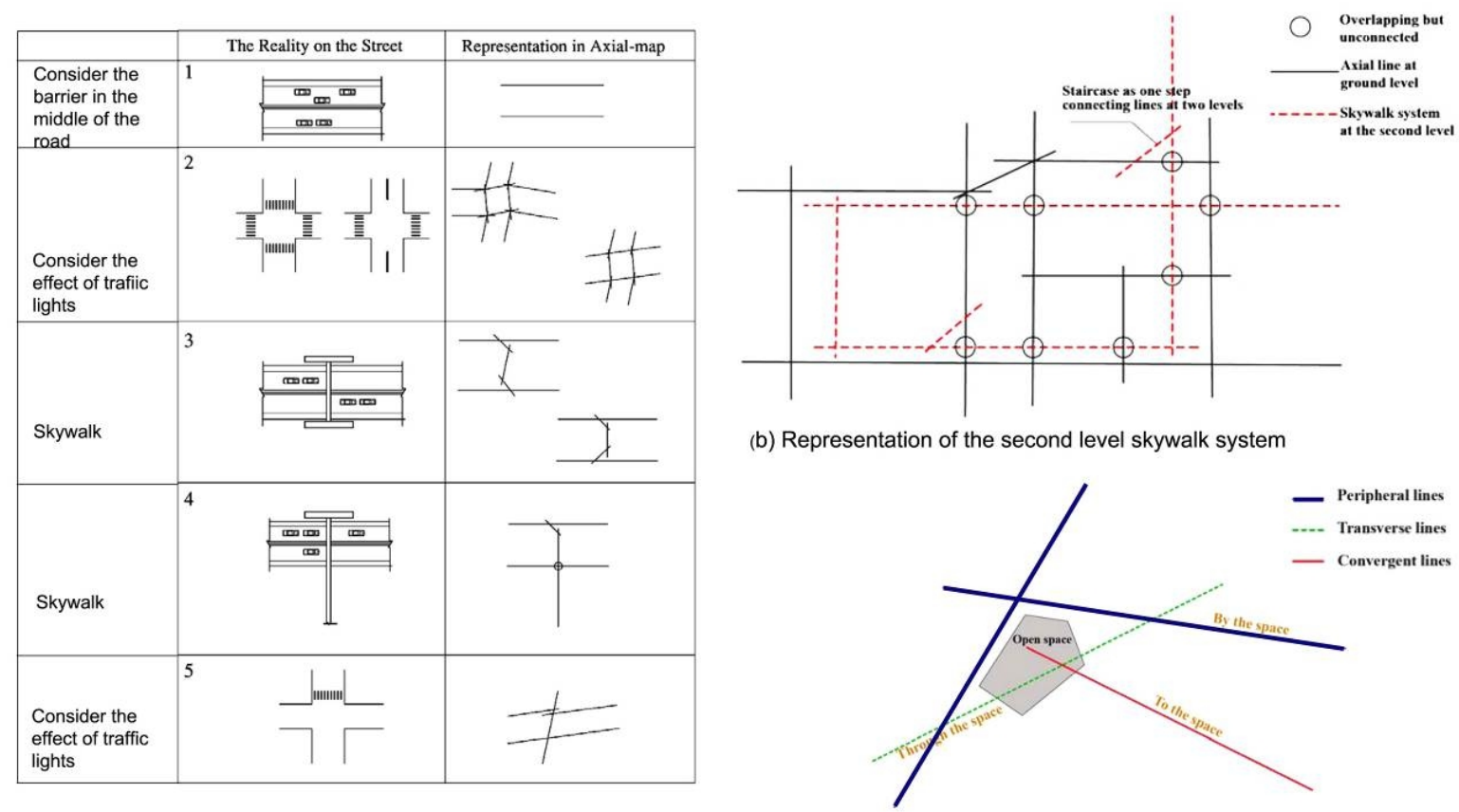

(a) Principles for axial line mapping

Fig. 3: Principles for axial mapping in Wanchai

\section{Configurational analysis of Wanchai District of Hong Kong}

The axial map (Fig. 4) illustrates the distribution of global integration ( Rn) across the Wanchai district. The most integrated lines are concentrated in the area between Gloucester Road and Johnston 
Road, the "Planned grid". The most integrated lines, colored red, comprise Gloucester Road South, Johnston Road and the Skywalk running through several street blocks from the south to the north; while the most segregated lines in purple are mainly located in the north along the waterfront and in the western zone. In general, the global integration $(\mathrm{Rn})$ value of the system tends to spread over a wide range, but do not essentially transverse from the central to the peripheral areas. They appear to be confined by the major roads, for example, Gloucester Road. This implies that Gloucester Road is a barrier, constraining the penetration of integration across the road, causing the "Sparse grid" to its north to have poor connection to the whole urban system. The mean global integration of the whole urban layout is 0.5102 , lower than some other cities. For example, the mean integration of London is about $0.765^{3}$, suggesting the spatial structure of Wanchai as a whole has a comparatively low level of accessibility.

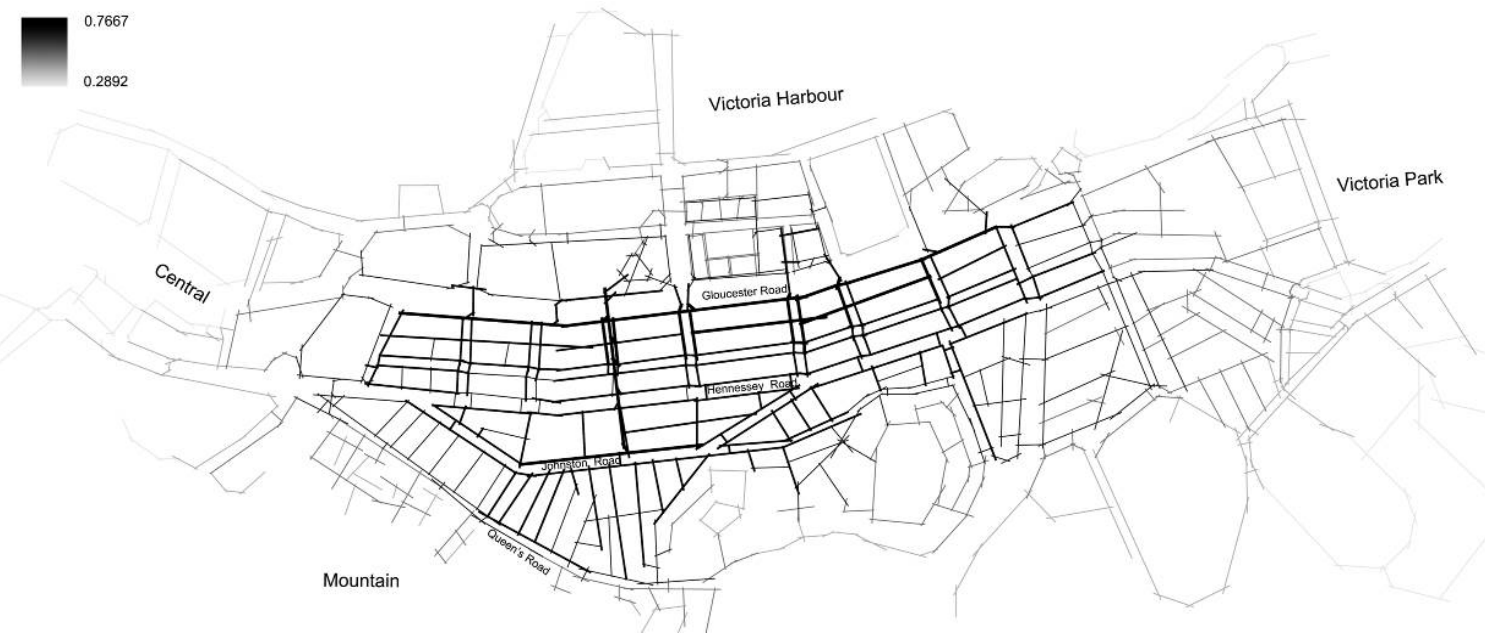

Fig. 4: Global integration map of Wanchai

As illustrated by Fig. 5(a,b,c), the core is mainly concentrated in the area between Johnston Road and Gloucester Road, and the core of Wanchai forms a 'ring' shape, running along Gloucester Road South, Kena Road, Hennessy Road and then Johnston Road, with the lines inside the 'ring' having higher integration values than the outside. When the core analysis is concerned with the $20 \%$ most integrated lines of the whole system, the 'ring' tends to form a complete circle, with more lines inside the ring as part of the core. Until the core is expanded to the $25 \%$ most integrated lines, the 'ring' begins to leak outwards to the south, with almost all the lines inside the 'ring' belonging to the core. However, few lines are found to be extended to the north. In this sense, it may be inferred that the continuity between Area 1 and Area 2 is stronger than that between Area 2 and Area 3. In this situation, theoretically, people could move more smoothly from core to Area 1, and vice versa; but to Area 3, the movement may be interrupted.

In contrast to $\mathrm{Rn}$, local integration (R3) indicates the "relative accessibility" of particulars lines with reference to their immediate neighbors. As a result, a different distribution pattern is found from the global integration, where the local integrators tend to be dispersed over the whole plan layout (Fig. $5 \mathrm{~d})$. As far as the top $15 \%$ locally integrated lines are concerned, the local integrators are mainly located along Queen's Road, Johnston Road, Lockhart Road, Gloucester Road South and the Skywalk linking Wanchai South and North, implying that, theoretically, they are the more accessible places with reference to their neighbors. When the analysis is concerned with the $20 \%$ most locally integrated lines, Hennessy Road is included. When imposing local integration maps upon the global one, few overlapping between them is found, implying that the locally integrated lines are not necessarily 
integrated globally, and vice versa. The low degree of consistency between the two scales of integration has implied a poor local and global relation of the layout.

\section{Defining the accessibility of open spaces in relation to spatial configuration}

\section{Accessibility on the global level}

Following the configurational analysis, this study commences to evaluate the accessibility of sample spaces by investigating the main lines of sample spaces. As defined, main line refers to the one that has the highest Rn value among all the lines interfacing the space. It is assumed that if a space is interfaced by the lines with higher integration values, it is more accessible from all the other parts of the urban system. Consequently, the data (Table-1) shows that the main line of thirteen sample spaces tends to demonstrate higher integration values than the mean of the whole system (0.5102) except that of Fenwick Waterfront. In addition, as far as all axial lines that interface the spaces are concerned, twelve sample spaces have their Rn strength of all lines above 1, with Hennessy pocket park ranking first (1.301); whereas two open spaces have an Rn strength of less than 1. They are the Hyatt Hotel Garden (0.950) and Fenwick Waterfront (0.869), both of which are located in the north part of Wanchai near the waterfront.

Table 1: Accessibility measurements on global level

\begin{tabular}{|c|c|c|c|c|c|c|}
\hline Name of space & Rn main line & $\begin{array}{l}\text { Rn strength of all } \\
\text { lines }\end{array}$ & $\begin{array}{l}\text { Depth to } 15 \% \text { or } \\
20 \% \text { R3 lines }\end{array}$ & $\begin{array}{l}\text { Depth to } 15 \% \\
\text { Rn core }\end{array}$ & $\begin{array}{l}\text { Depth to } 20 \% \\
\text { Rn core }\end{array}$ & $\begin{array}{l}\text { Depth to } 25 \% \\
\text { Rn core }\end{array}$ \\
\hline Lichit & 0.596 & 1.168 & 2 & 4 & 3 & 2 \\
\hline Lunfat & 0.596 & 1.168 & 2 & 4 & 3 & 2 \\
\hline Amoy & 0.642 & 1.259 & 2 & 2 & 1 & 1 \\
\hline Spring & 0.630 & 1.191 & 2 & 2 & 2 & 1 \\
\hline Tai Wo & 0.630 & 1.235 & 2 & 2 & 2 & 1 \\
\hline Hennessey & 0.692 & 1.301 & 1 & 1 & 1 & 1 \\
\hline Southorn & 0.704 & 1.286 & 1 & 1 & 1 & 1 \\
\hline Wanchai Park & 0.629 & 1.070 & 2 & 2 & 2 & 1 \\
\hline Lockhart & 0.650 & 1.244 & 1 & 2 & 1 & 1 \\
\hline CRC blg. & $0.540(0.554)$ & $1.030(1.154)$ & 3 & 5 & 4 & 4 \\
\hline Central Plaza & 0.649 & 1.191 & 1 & 2 & 1 & 1 \\
\hline Gloucester & 0.649 & 1.230 & 1 & 2 & 1 & 1 \\
\hline Hyatt & 0.532 & 0.950 & 3 & 6 & 5 & 5 \\
\hline Waterfront & 0.472 & 0.869 & 8 & 9 & 8 & 7 \\
\hline
\end{tabular}

Note: ( ) represent the occasion when lines on the second level are also considered. Rn strength of interfacing lines refers to the global integration value of the main line divided by the mean of the whole system.

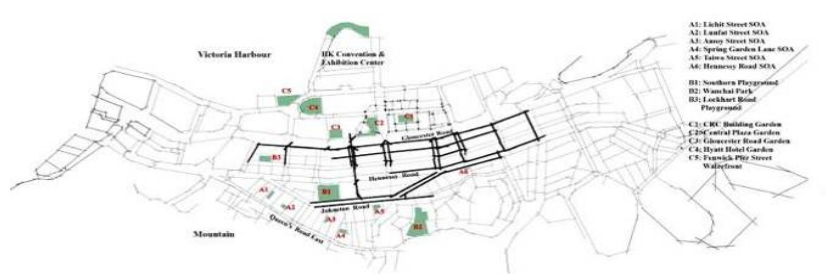

(a) Depth to $10 \%$ Rn core

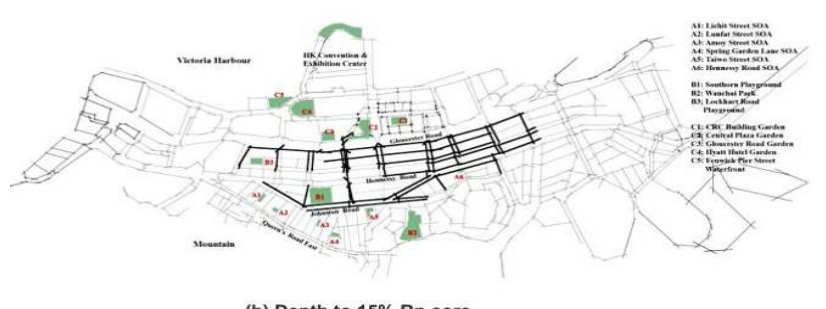

(b) Depth to $15 \% \mathrm{Rn}$ core

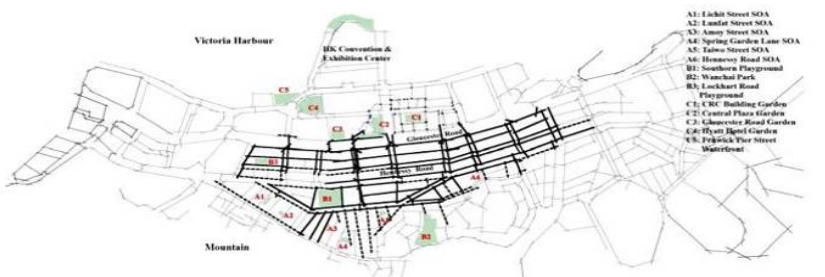

(c) Depth to $20 \%$ and $25 \% \mathrm{Rn}$ core

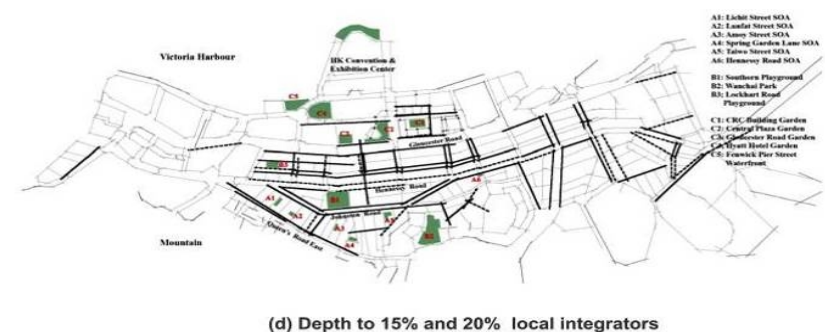

(d) Depth to $15 \%$ and $20 \%$ local integrators

Fig. 5: Depth of open spaces to Rn core and local integrators 
When examining the location of sample spaces to the $15 \%$ and $20 \%$ syntactic core within the overall spatial layout, the analysis illustrates that Southorn Playground and Hennessy Road SOA have at least one of their interfacing lines located in the $15 \% \mathrm{Rn}$ cores, implying two spaces are located within or near the most accessible place of the district. Seven cases at least have one line 2 depths away from the 15\% Rn core; they are Amoy St. SOA, Spring Garden Lane SOA, Taiwo SOA, Wanchai Park, Lockhart Playground, Central Plaza Garden, and Gloucester Road Garden, respectively. The other three open spaces with no lines in or near the core are distributed at least 5 depths away, mainly in the areas to the north of Gloucester Road, implying that they are relatively remote and inaccessible in terms of their relation to the syntactic core. These three spaces are CRC Building Garden, Hyatt Hotel Garden and Fenwick Pier St. Waterfront. The remaining two cases, Lichit St. SOA and Lunfat St. SOA, which are distributed in the "Traditional grid", have 4 depths away from the $15 \%$ syntactic cores. When considering the $20 \% \mathrm{Rn}$ core within the whole system, apart from previous cases with at least one of their interfacing lines belonging to the core (Southorn Playground and Hennessy Road SOA), another four open spaces, Amoy St. SOA, Lockhart Playground, Central Plaza Garden, and Gloucester Rd. Garden, have at least one interfacing line belonging to the $\mathrm{Rn}$ core, indicating these spaces are comparatively accessible with reference to their topological distance to the core.

The global location can be also measured by examining the relationship between the interfacing lines of the sample spaces and the 15\% (20\%) most locally integrated lines (Fig. 5d). As a result, six of fourteen sample spaces have at least one of their interfacing lines belonging to the $15 \%$ and $20 \%$ local integrators, implying that they are relatively accessible from their neighbors. The six spaces are Southern Playground, Hennessy Road SOA, Lockhart Road Playground, Gloucester Road Garden, CRC Building Garden and Central Plaza Garden. While the other six cases, Lichit, Lunfat, Amoy, Spring, Taiwo SOA, and Wanchai Park, have at least one of their interfacing lines two depth away from the $20 \%$ local integrators, leaving the remaining two cases comparatively remote and separated, with their depth to local integrators oscillating between three and eight.

\section{Accessibility on the local level}

Table 2: Accessibility measurements on the local level

\begin{tabular}{|c|c|c|c|c|c|c|c|}
\hline \multirow[t]{2}{*}{ Name of space } & \multicolumn{3}{|c|}{ No. of interfacing lines } & \multirow{2}{*}{$\begin{array}{l}\text { Strategic } \\
\text { value }\end{array}$} & \multirow{2}{*}{$\begin{array}{c}\text { Local strategic } \\
\text { value }\end{array}$} & \multirow{2}{*}{$\begin{array}{c}\text { Mean of strategic } \\
\text { value }\end{array}$} & \multirow{2}{*}{$\begin{array}{c}\text { Mean of local strategic } \\
\text { value }\end{array}$} \\
\hline & Con. lines & Peri. lines & Trans. lines & & & & \\
\hline Lichit & & 1 & & 0.596 & 2.209 & 0.596 & 2.209 \\
\hline Lunfat & & 1 & & 0.596 & 2.209 & 0.596 & 2.209 \\
\hline Amoy & & 1 & & 0.642 & 2.556 & 0.642 & 2.556 \\
\hline Spring & & 3 & & 1.824 & 6.418 & 0.608 & 2.139 \\
\hline Tai Wo & & 2 & & 1.261 & 4.662 & 0.630 & 2.331 \\
\hline Hennessey & 1 & 2 & & 1.327 & 5.527 & 0.664 & 2.763 \\
\hline Southorn & & 5 & & 3.280 & 13.044 & 0.656 & 2.609 \\
\hline Wanchai Park & 2 & 3 & & 3.763 & 10.093 & 0.538 & 1.442 \\
\hline Lockhart & & 3 & & 1.904 & 8.197 & 0.635 & 2.732 \\
\hline CRC blg. & & $4+(3)$ & & 3.709 & 15.740 & 0.530 & 2.249 \\
\hline Central Plaza & & $5+(3)$ & (2) & 5.906 & 20.951 & 0.591 & 2.095 \\
\hline Gloucester & & 3 & & 1.264 & 5.845 & 0.632 & 2.922 \\
\hline Hyatt & & $8+(2)$ & & 5.345 & 19.277 & 0.486 & 1.752 \\
\hline Waterfront & 1 & 3 & & 2.661 & 10.193 & 0.443 & 1.699 \\
\hline
\end{tabular}

Note: ( ) represent the occasion when lines on the second level are also considered

The examination of local accessibility of the sample spaces starts with a description of the interfacing lines in terms of their types, number and strategic values. It is assumed that the more the number of the lines the space is interfaced or higher strategic values the lines have, the higher level of use the space would demonstrate. As a result, the interfacing lines of the sample spaces are presented in Table-2. To involve the contextual characteristics of Wanchai District into consideration, the type of interfacing lines is classified according to the way they interface with the spaces, such as convergent lines, peripheral lines and transverse lines (Fig.3c). 
Totally, 58 lines are found interfacing the fourteen sample open spaces, including those on the second level (10 lines). As far as the type of the interfacing lines are concerned, 88\% (a total of 52 lines) are peripheral lines, presenting in all cases, 4 convergent lines presenting in three cases (Wanchai Park, Hennessy Rd. SOA, and Fenwick St. Pier Waterfront), with 2 transverse lines in one case (Central Plaza Garden). This finding is quite different from the studies in traditional European towns, where interfacing lines are mainly convergent lines. For example, for the traditional squares in European towns, most of the interfacing lines $(68 \%)$ are convergent lines, with $26 \%$ of peripheral lines and $6 \%$ of transverse lines[17].When looking at the number of interfacing lines, three cases: Lichit St. SOA, Lunfat St. SOA and Amoy St. SOA have one interfacing line only, while the other two sample spaces: Central Plaza Garden and Hyatt Hotel Garden have more than 10 interfacing lines, including those on the second-level, leaving the remaining nine sample open spaces with their interfacing lines numbering from 2 to 7. Despite the relatively high number of axial lines interfacing with the open spaces, the great predominance of peripheral lines in the samples presents a distinct relationship between the open spaces and surrounding networks in the Wanchai District. Since the type of interfacing lines is associated with the type of pedestrian movements, it may be inferred that the pedestrian networks of Wanchai do not lead pedestrians into or through the spaces as convergent and transverse lines do. Instead, the networks encourage pedestrians to pass by.

The analysis proceeds by investigating the strategic and local strategic values of sample spaces (Table-2). Consequently, strategic values are found to vary significantly from different sample spaces, from 0.596 to 5.906. Specifically, five cases have their strategic values higher than 3 , implying that they are more accessible in terms of the association to networks. These spaces include Southorn Playground, Wanchai Park, CRC Building Garden, Central Plaza Garden, Hyatt Hotel Garden. Contrastingly, three open spaces have their strategic values less than 1 , with the remaining six cases having their values between 1 and 3. Similar variation can be found for local strategic values among the sample spaces, with their values ranging from 1.857 to 11.806 .

\section{The interrelationship between accessibility and use of open spaces}

In order to examine if the already defined accessibility measurements have implications for the performance of open space, a correlation analysis is carried out in this section. The performance of open space will focus on the level of use inside the spaces. Again, the analysis is carried out on two scales: all samples as a whole and samples in different grid patterns. The data concerning the level of use of sample spaces was mainly obtained by site observation. Once the data were obtained from the observations, they were sorted and mainly computed into mean number of users (mean use) and mean use density (Table-3). The mean use is defined as the total number of users divided by the number of observation rounds; while mean use density is obtained by dividing the value of mean use by the area of the space.

Table 3: Mean number of use and Mean use density of sample open spaces

\begin{tabular}{lcccccc|ccccccccc}
\hline & \multicolumn{4}{c}{ Pocket Parks } & & \multicolumn{3}{c|}{ Playgrounds } & \multicolumn{3}{c}{ Gardens \& Waterfront } \\
\cline { 2 - 13 } & Lichit & Lunfat & Amoy & Spring & $\begin{array}{c}\text { Tai } \\
\text { Wo }\end{array}$ & Hennessey & Southorn & $\begin{array}{c}\text { Wanchai } \\
\text { Park }\end{array}$ & Lockhart & $\begin{array}{c}\text { CRC } \\
\text { Blg. }\end{array}$ & $\begin{array}{c}\text { Central } \\
\text { Plaza }\end{array}$ & $\begin{array}{c}\text { Gloucester } \\
\text { Hyatt } \\
\text { Hotel }\end{array}$ & $\begin{array}{c}\text { Water } \\
\text { front }\end{array}$ \\
\hline $\begin{array}{l}\text { Mean } \\
\text { use }\end{array}$ & 5.35 & 4.65 & 0.90 & 18.45 & 17.65 & 8.65 & 221.45 & 102.15 & 33.47 & 32.68 & 20.84 & 12.32 & 18.21 & 12.68 \\
$\begin{array}{l}\text { Mean } \\
\text { density }\end{array}$ & 0.011 & 0.012 & 0.0024 & 0.030 & 0.014 & 0.056 & 0.025 & 0.011 & 0.018 & 0.0123 & 0.0036 & 0.0043 & 0.0021 & 0.0024 \\
\hline
\end{tabular}




\section{Global accessibility and use of open spaces}

When correlating the use of open spaces with their global accessibility measurements, the analysis reveals that there is no association between the uses and the integration value of main lines, implying that the use of open space is independent of the property of main lines. When concerning the depth to $\mathrm{Rn}$ core, no correlation is revealed for the mean use of the spaces. In like manner, no influence is to be found on their mean use density. In light of the results, it could be inferred that the level of use of the sample spaces is not the function of their topological distance (Depth) to the syntactic core, theoretically the most accessible and used area within the urban system. However, a trend is still to be identified; that is, those located in or closer to the syntactic core, theoretically the most accessible place of the overall layout, tend to be more intensively used, although those located remotely from the core can also perform well.

When investigating the relationship between the depths of the spaces to the $15 \%$ and $20 \%$ most locally integrated lines (local integrators) and their level of use, once again, no correlation can be found between the two set of variables, no matter whether mean use or mean use density is concerned. When dealing with the analysis according to different grids, likewise, no correlation is to be found between two set of variables, further proving that the use of open spaces is independent of their relation to spatial configuration on the global level.

\section{Local accessibility and use of open spaces}

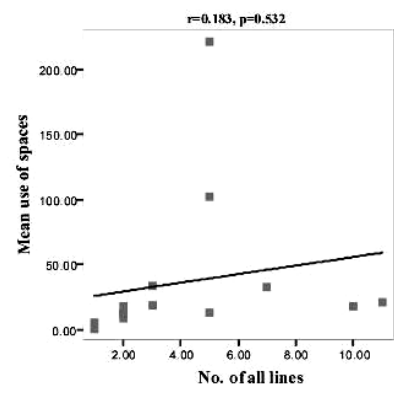

(a) Scattergram of Mean use and No. of all lines

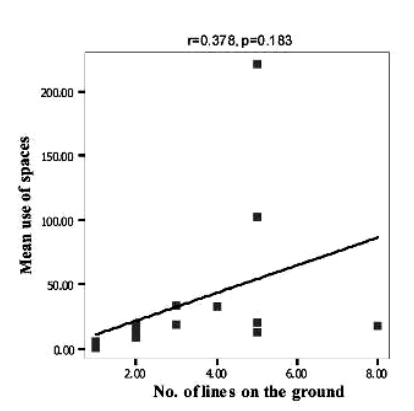

(b) Scattergram of Mean use and No. of lines on the ground

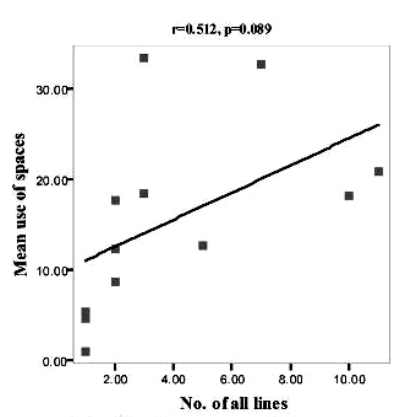

(c) Scattergram of Mean use and No. of all lines (with Southorn \& Wanchai excluded)

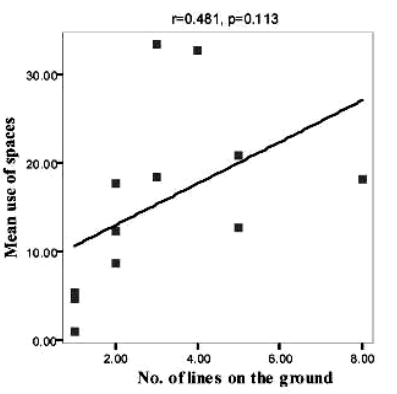

(f) Scattergram of mean use and No. of lines on the ground (with Southorn \& Wanchai excluded)

Fig. 6: Correlation between Mean use and no. of interfacing lines

The analysis starts by examining the relationship between the number of the axial lines that interface with the spaces and use of open space. As a result, no association is found between their mean use and the number of all interfacing lines as far as the entire sample spaces are concerned (Fig. 6), neither for the number of peripheral lines and lines on the ground. When reviewing the relevant scattergrams, the distribution of the two top-right points (representing Southorn Playground and Wanchai Park) seems to suggest that the result may be a fortunate outcome of the two points. When excluding them in the analysis, the scattergram shows that the mean use of 12 sample spaces is weakly correlated with the number of peripheral lines, with $\mathrm{r}=0.580$ and $\mathrm{p}=0.048$, and no correlation is found with the number of lines under the two circumstance (all interfacing lines and lines on ground level respectively). Likewise, the analysis shows that the mean use density is irrelevant to the number of interfacing lines in all the circumstances.

When carrying out the analysis based on different grids, a different correlation pattern is found from the above analysis. In "Traditional grid", a correlation is found between mean use of the sample spaces and the number of all interfacing lines, which are all peripheral lines on ground level, with 
$\mathrm{r}=0.911$ and $\mathrm{p}=0.031$, implying the more lines that interface the space, the higher the mean use is found inside the space. Also, the analysis shows that mean use density is also correlated with the number of all lines in "Traditional grid", with $r=0.901$ and $p=0.037$ for all lines. When concerning the sample open spaces located in "Dense grid", the results initially show a significant correlation between the number of all interfacing lines. However, when Southorn Playground, as an extreme case influencing the distribution of scatters, is excluded from the analysis, the linear relationship is only found between mean use of the space and the number of all interfacing lines. Furthermore, no correlation is to be found between mean use density and the number of lines.

To examine whether a similar correlation is presented for the open spaces located in "Sparse grid", the study then correlated the level of use of the sample spaces with their number of interfacing lines under two conditions (all lines and lines on ground level). The results initially showed no correlation between these variables. However, when CRC Garden as an extreme case, is excluded from the analysis owing to its unique location in the scattergram, the analysis then shows that the mean use is correlated with both the number of all interfacing lines (including the lines on the second level), yet with no association to the number of lines on ground level alone. In light of the results found in the "Sparse grid", several empirical statements can be made. Firstly, the more lines that interface with the spaces, the higher the mean use can be recorded inside the spaces, when CRC Garden is excluded due to its internal facilities. Secondly, the interfacing lines on the second level also play a role in the use of the space, because only the number of lines on the ground is inadequate to account for the variation of their mean uses. Once again, no correlation is to be found between mean use density and number of lines in all situations. In this regard, it may be concluded that mean use density is not an effective measurement to investigate the relationship between the accessibility and the use of open space in this study.

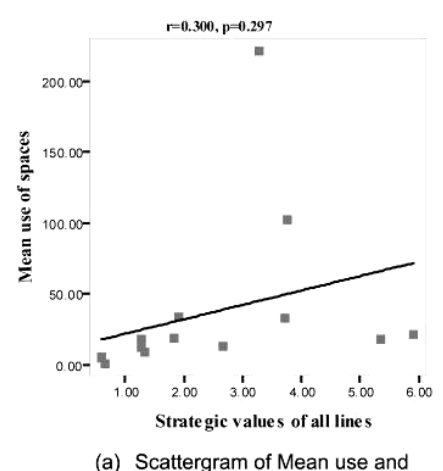

of Mean use and strategic value of all lines

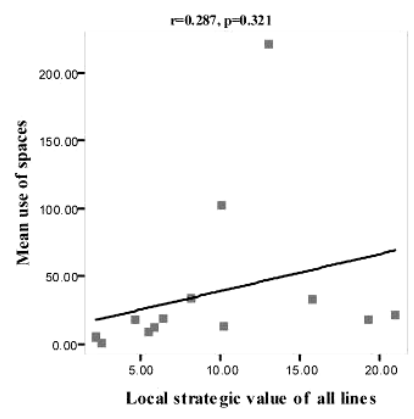

(b) Scattergram of Mean use and local strategic value of all lines

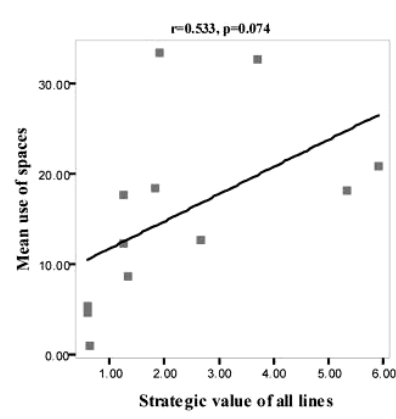

(c) Scattergram of Mean use and strategic value of all lines (with Southorn \& Wanchai excluded)

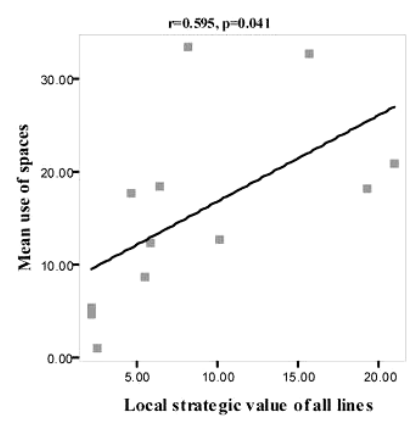

(d) Scattergram of mean use and local strategic value of all lines (with Southorn \& Wanchai excluded)

Fig. 7: Correlation between Mean use and strategic values and local strategic values

The data for strategic values have been computed with regard to two situations: all interfacing lines, and lines on the ground level (only applied to "Sparse grid"). The first step is to correlate the level of use of all the sample spaces (including mean use and mean use density) against their strategic values of all interfacing lines. The analysis initially shows no correlation between two set of variables (Fig. 7). Likewise, no correlation is to be found between the level of use and local strategic values. This finding obviously contradicts the conclusion drawn by Hillier [16] and Campos [17]. However, when two special cases, Southorn Playground and Wanchai Park are excluded due to their extremely high mean use, the analysis shows that the mean use does not show correlation with the strategic value of all lines, but is weakly associated with their local strategic values. This seems to suggest that the mean use is more dependent on the local properties of their interfacing lines. Once again, mean use density is 
irrelevant with both local and global strategic values. Either, no correlation is to be found for the lines on the ground level.

As far as different urban grids are concerned, there is a correlation between mean use of the open spaces located in "Traditional grid", and the strategic values of all their interfacing lines, which are all peripheral lines on ground level, implying that the mean number of users inside the sample spaces throughout the day is consistently the function of the strategic value of all its interfacing lines in "Traditional grid". Similarly, a correlation is found for the local strategic value of all interfacing lines. When the correlation analysis is carried out based on "Dense grid", the evidence shows that the mean use of the open spaces is still significantly correlated with both their strategic value and the local strategic value of all interfacing lines, suggesting the higher the local and global strategic values, the larger the mean number of users inside the open spaces are recorded. Neither correlation is found when considering mean use density of the spaces, further suggesting that it is not an effective measurement to describe the level of use of the sample spaces in this study.

In contrast to the analysis in "Traditional grid" or "Dense grid", the analysis focused on "Sparse grid" shows that in all situations (including all interfacing lines or lines on the ground), the levels of use (mean use and mean use density) and strategic values are independent variables, seemingly implying that the performance of the open spaces in "Sparse grid" is not necessarily the function of the sum Rn value of their interfacing lines. However, when CRC Garden is excluded, the analysis reveals that the mean number of users inside the four sample spaces is well correlated with the strategic value of all lines, but no correlation is found for the lines on ground level. If the result is reliable, it may be inferred that the use of the open spaces located in "Sparse grid" is also the function of properties of their interfacing lines, especially their strategic values. Likewise, with the exception of CRC Garden, mean use of the spaces is well correlated to local strategic value of all lines, but none is found for lines on ground level, implying that the skywalks over the spaces may have played a role in their performance; because lines on the ground level alone are insufficient on account of the variation of their mean use.

\section{Conclusion}

In light of the above discussion, it is confirmed that urban morphology plays a role in the access and use of open spaces in a variety of ways. More specifically, the access and use of open spaces is influenced by their location within the overall spatial layout and the way in which they are related to the surrounding pedestrian networks to different extents.

The accessibility model formulated in this study has proven to be effective. This can be explained from several aspects. First, the concept of accessibility defined in the model has comprehensively described the relationship between open space and surrounding morphologies. Therefore, the model is more realistic and can be used to evaluate or account for the accessibility problem more precisely and systematically. Secondly, when the model is used to examine the accessibility and use of sample spaces in the Wanchai District of Hong Kong, it has revealed a number of information that cannot be reflected by the conventional accessibility model. In comparison with previous accessibility related studies, the study model helps to provide a precise understanding as to how the accessibility and use of open spaces are conditioned in the real circumstances.

This study focuses on the open spaces in the Wanchai District of Hong Kong, where the urban fabric demonstrates a spatial and functional complexity and diversity. With the help of research method formulated in this study, it has revealed that the accessibility and use of open spaces in Wanchai is not a simple issue. Different spatial morphologies can have varying impacts on the use of open spaces. 
Among all the morphological properties, the determining factors include the number, strategic values and local strategic value of all the interfacing lines of a space.

\section{Acknowledgements}

This research was financially supported by National Natural Science Foundation of China (51138004), State Key Laboratory of Subtropical Building Science Research, South China University of Technology (2013ZC15 \& 2016ZB17) and "Guangzhou Ceremony" and Guangzhou History and Culture Research (2015GZY25)

\section{Notes:}

1. A 'segment-line' city was used to describe the urban structure of metropolis of Hong Kong (Source: Hong Kong: Alternative Metropolis, Space Design, No. 330, 1992, 42-43).

2. Source: Chapter 4: Recreation, Open Space and Greening, Hong Kong Planning Standards and Guidelines, 2005.

3. The data is from the analysis by Bill Hillier. (1989). The Architecture of the Urban Object, Ekistics, 334-335.

\section{Reference}

[1] Information on http://www.pland.gov.hk/press/speeches/highden_dev.pdf, accessed on November, 2014

[2] M. Chow. An Evaluation of Existing Open Space in Hong Kong: GIS \& Location Allocation Modeling Approach, M. Sc. Dissertation, University of Hong Kong, Hong Kong (1994).

[4] S. Carr, F. Mark, G. Leanne, and M.A. Stone. Public Spaces, Cambridge University Press, Cambridge (1992).

[3] R. Kaplan and S. Kaplan. Restorative Experience: The Healing Power of Nearby Nature, The Meaning of Gardens, Edited by M. Francis and R. Hester, MIT Press, Cambridge (1990).

[5] G. Godbey, R. Alan and S.W. J. The Benefits of Local Recreation and Park Services, A Nationwide Study of the Perceptions of the American Public, Leisure Studies Program, Pennsylvania State University for the National Recreation and Park Association, Pennsylvanis (1992)

[6] M. Leveratto. Urban Planning Instruments to Improve Winter Solar Access in Open Public Spaces, Environmental Management \& Health, Vol. 13(4) (2002), pp. 366-372.

[7] B. Hillier. Space is the Machine: A Configurational Theory of Architecture, Cambridge University Press, Cambridge (1996).

[8] B. Hillier and J. Hanson. The Social Logic of Space, Cambridge University Press, Cambridge (1984).

[9] W. Whyte. City - Rediscovering the Center, Doubleday, New York (1988).

[10] A. Burden. Greenacres Park, Project for public spaces, New York (1977).

[11] J. Gehl. A Changing Street Life in a Changing Society, Place-A Quarterly Journal of Environmental Design, Vol. 6(1989), pp. 8-17.

[12] D. R. Ingram. The Concept of Accessibility: A search for an Operation Form, Regional Studies:

The Journal of the Regional Studies Association 5, no. 2 (1971), P. 101-107.

[13] K. Lynch. A Theory of Good City Form, MIT Press, Cambridge (1981). 
[14] B. Jiang, C. Claramunt, and M. Batty. Geometric Accessibility and Geographic Information: Extending Desktop GIS to Space Syntax, Computers Environment and Urban Systems 23 (1999), pp.127 -146.

[15] J. Peponis. Space, Culture and Urban Design in Late Modernism and After, Ekistics 56, no. 334 (1989), pp. 93-108.

[16] B. Hillier. Mansion House Squares Inquiry-proof of Evidence, Unit for Architectural Studies, Bartlett Scholl of Architecture and Planning, University College London (1984).

[17] M. B. Campos. Urban Public Spaces: A study of the Relation between Spatial Configuration and Use Patterns, Ph. D. Dissertation, University College London (2000).

[18] D. Chang. Integrated Multi-level Circulation Systems in Dense Urban Areas: The Effect of Complex Spatial Designs on Multi-level Pedestrian Movement, Ph.D. Dissertation, University College London, London (2000). 